\title{
How business cycles affect the healthcare sector: A cross-country investigation
}

\author{
Kathleen Cleeren $^{\mathbf{a}^{*}}$ \\ Lien Lamey \\ Jan-Hinrich Meyer ${ }^{c}$ \\ Ko De Ruyter
}

${ }^{a}$ Maastricht University, Tongersestraat 53, 6211 LM Maastricht, the Netherlands.

${ }^{\mathrm{b}}$ KU Leuven, Naamsestraat 69, 3000 Leuven, Belgium.

c Instituto Technológico y de Estudios Superiores de Monterey (ITESM) Campus

Guadalajara, Av. General Ramón Corona No. 2514, Col. Nuevo México CP 45201, Zapopan, Jalisco, Mexico.

* Corresponding author. Tel.: +31 4338 83624. E-mail address:

k.cleeren@maastrichtuniversity.nl (K.Cleeren).

Keywords: business cycle, healthcare expenditures, mortality, healthcare systems. 


\begin{abstract}
The long-term relationship between the general economy and healthcare expenditures has been extensively researched, to explain differences in healthcare spending between countries, but the mid-term (i.e., business-cycle) perspective has been overlooked. This study explores business-cycle sensitivity in both public and private parts of the healthcare sector across 32 countries. Responses to the business cycle vary notably, both across spending sources and across countries. Whereas in some countries, consumers and/or governments cut back, in others, private and/or public healthcare buyers tend to spend more. We also asses long-term consequences of business-cycle sensitivity, and show that public cost cutting during economic downturns deflates the mortality rates, whereas private cut backs increase the long-term growth in total healthcare expenditures. Finally, multiple factors help explain variability in cyclical sensitivity. Private cost cuts during economic downturns are smaller in countries with a predominantly publicly funded healthcare system and more preventive public activities. Public cut backs during contractions are smaller in countries that rely more on tax-based resources rather than social health insurances.
\end{abstract}




\section{INTRODUCTION}

Because of its huge social and economic importance, the healthcare sector receives a lot of research attention. Among the biggest concerns in this field are exploding healthcare expenditures, which tie up funds that could be used for other purposes or increase debt levels. Although higher healthcare expenditures can reduce a country’s mortality rate, nations struggle to keep healthcare expenditures under control; they have outpaced the growth of the general economies of most Western countries in recent decades (Mladovsky et al. 2012). ${ }^{1}$

The (long-run) relationship between healthcare expenditures and the general economy has been studied extensively in an attempt to explain differences across countries in their healthcare spending levels and growth (for a review, see Gerdtham and Jönsson 2000). Yet a business-cycle (mid-term) perspective, may lead to substantially different conclusions about the link between the economy and healthcare, with important policy implications (Narayan and Narayan 2008). This perspective is lacking from extant research.

Although, a priori, the healthcare industry may appear unrelated to temporary economic up- and downswings - people’s medical needs should not fluctuate with the business cycle - anecdotal evidence during the latest recession indicates otherwise. According to Deloitte’s 2011 Survey of Healthcare Consumers, about half of the respondents in all countries surveyed (except for Luxembourg) indicated that the economic downturn affected their willingness to spend on healthcare. In the UnitedStates, for example, $41 \%$ of respondents indicated that the poor economic climate made them more cautious about such spending. Yet, about half of all respondents worldwide (except for the United Kingdom, Canada, and China)

\footnotetext{
${ }^{1}$ Between 2009 and 2011, one-third of the OECD countries experienced negative growth in health care expenditures (OECD 2013). In our study 17 of the 32 countries exhibit at least one year in which their total healthcare expenditures dropped between 2009 and 2011. Yet, for 13 of these 17 countries, the drop was temporary and linked to the business cycle, whereas the long-term trends remained positive. We observe decreases in both the cyclical and the long-term components of healthcare expenditures only in Greece, Iceland, Ireland and Luxembourg. To test if these examples represent a permanent phenomenon, we would require sufficient observations after the economic slowdown, which are not yet available.
} 
noted increased household spending on healthcare during the global recession, possibly because economic downturns can harm people's mental health, due to their increased anxiety about losing their jobs, or about the future in general (Tefft 2011). Nonetheless, Ruhm (2003) demonstrates that mortality rates typically are lower during tough economic times.

In terms of public spending, we can also observe varying responses to the latest economic crisis (Strine et al. 2008). The U.S. government introduced a $\$ 150$ billion stimulation package for the healthcare industry as part of its Recovery and Reinvestment Act, and Norway has invested in reforming and improving its healthcare systems to avoid social inequalities. In contrast, countries such as Estonia, Ireland, and Iceland recently introduced big cuts in their public healthcare expenditures. Such anecdotal evidence in aggregate seems to imply that both private and public healthcare expenditures may be related to cyclical upand down movements in the general economy (i.e., the business cycle), such that differences between countries and spending sources are likely.

Beyond establishing a foundational insight, regarding whether healthcare spending is sensitive to the business cycle, policy makers also need to understand how these cyclical fluctuations affect the sector in the long run. When private healthcare buyers need to reduce their healthcare expenditures, they often do so in less immediately urgent areas, such as prevention programs and procedures that can be postponed (e.g., quit-smoking programs, diabetes and cancer prevention; Mladovsky et al. 2012). These decisions may help reduce healthcare expenditures during bad times, but failing to prevent or treat problems over time may have negative impacts on people’s long-term health status. Moreover, to restore their health status to the level they had before the crisis, people might need to overcompensate, which would entail a long-term impact in the form of rising healthcare expenditures.

For public entities, cutting healthcare expenditures might not necessarily result in negative long-term consequences. Governmental cuts in healthcare expenditures are necessary 
from time to time, to increase efficiency in the sector. Such moves likely are easier to justify when the overall economy turns sour (Lane 2003b), because an economic crisis signals an opportunity for innovation and new approaches to efficient healthcare that might not exist otherwise (Thorlby 2011). When these reforms lead to improved efficiency in the sector, the spending on healthcare may decrease in the long run, due to public budget cuts. In addition, mortality rates decrease during economic downturns (Ruhm 2000, 2003, 2005), which makes public budget cuts even more appropriate. For example, many Canadian provincial governments cut their health budgets following an economic crisis in the 1990s, while simultaneously implementing structural reform of the sector, which led to lower mortality rates over time (Liu et al. 2001).

Finally, we need insights into which factors drive the cyclical sensitivity of healthcare expenditures. The healthcare system established by a country strongly determines its cost structure, and thus likely influences its cyclical sensitivity, for example. Public prevention spending also can promote healthcare usage through preventive activities, but the public debt level might decrease a country’s ability to act during an economic downturn.

Considering these various factors and necessary insights, we seek to answer three key research questions:

(i) Are private and public healthcare expenditures related to the business cycle?

(ii) Does cyclical sensitivity have long-term consequences, in terms of the mortality rate of the population and total healthcare expenditures?

(iii) Which factors explain across-country variability in cyclical sensitivity? 


\section{HEALTHCARE EXPENDITURES AND THE BUSINESS CYCLE}

An expansive body of research studies the relationship between healthcare expenditures and the general economy (gross domestic product [GDP]), in an attempt to explain cross-country differences (see Gerdtham and Jönsson (2000) for an overview of this literature).

In a pioneering study, Newhouse (1977) identified a strong positive relationship between healthcare expenditures and GDP, using a cross-sectional analysis of 13 OECD countries. His results cited GDP as the most important driver of healthcare expenditures. When time-series data on healthcare expenditures become available in the 1990s, more sophisticated analyses appeared, exploring whether this positive relationship between healthcare expenditures and GDP held over time. Several studies tested for long-run relationships on a country-by-country basis (e.g., Herwartz and Theilen 2003) or across countries using panel data techniques (e.g., Gerdtham and Loethgren 2000; McCoskey and Selden 1998). Despite some debate (e.g., Hansen and King 1996), most studies indicate that healthcare expenditures and GDP are co-integrated (Blomqvist and Carter 1997; Gerdtham and Loethgren 2000; Herwartz and Theilen 2003), such that they co-move in the long run. Overall, general economic activity remains the most consistent and widely used predictor of over-time developments in healthcare expenditures (Di Matteo and Di Matteo 1998).

The focus in most studies has been on the long-term relationship between the economy and healthcare expenditures, but some research also shows that interactions between the same variables can vary with different periodicities. For example, Baxter (1994) shows that the relationship between real exchange rates and real interest rate differentials does not exist in the short run (i.e., at high frequencies), but it is strong for both long-run and business-cycle (mid-run) periodicities. As the long-term relationship of healthcare expenditures and general economic activity does not necessarily translate in the same relationship at the business cycle perspective, more research is needed to determine the cyclical sensitivity of the sector. 
A rich research stream, led by Ruhm (2000, 2003, 2005), already has established the importance of the business cycle perspective for healthcare researchers (see also Gerdtham and Ruhm 2006; Miller et al. 2009). However, this research stream focuses on the business cycle sensitivity of people's health status or the mortality rate. To the best of our knowledge, no study has systematically analyzed the cyclical sensitivity of healthcare expenditures across a large sample of countries, as called for by Narayan and Narayan (2008).

Furthermore, recent research proposes separate analyses of healthcare expenditures for private consumers and government entities, because it is not clear whether the two sources develop in similar ways (Getzen 2000). Clemente et al. (2004) suggest that the long-term relationship between the overall economy and private and public healthcare expenditures evolve differently over time. Disentangling the private from public expenditures thus may lead to a more fine-grained picture of the sector.

Accordingly, we formulate several arguments about the likely direction of cyclical sensitivity of public and private expenditures.

Public Expenditures. Economic contractions might lead to cost cuts, or procyclical fluctuations, in public healthcare expenditures, for two reasons. First, countries might face severe budget constraints due to tumbling revenues and thus be forced to reduce their expenditures in all sectors (Stuckler et al., 2009). Second, downturns can provide justifications for making cuts in socially important sectors. As Lane (2003b) indicates, it is much harder for governments to prevent expenditure growth during good economic times than during downturns. Different institutions are less demanding in budget negotiations during downturns, because everybody knows that the amount to be distributed is much smaller. However, some evidence also suggests the opposite reaction of increasing public expenditures during contractions, or countercyclical sensitivity. Countries often adopt a 
classical Keynesian approach and try to stimulate the economy during tough times (Lane 2003b). Government stimulation packages usually contain general investments in infrastructure or other institutions of common interest. Because healthcare has great social and economic importance, it is a useful target for such investments.

Private Expenditures. Private expenditures also might relate to the business cycle. On the one hand, private consumers economize on their spending in general during economic downturns (i.e., behave procyclically) (Katona 1974). In the healthcare sector, they buy more generic pharmaceuticals or postpone treatments with higher out-of-pocket payments to save money (Neumayer 2004). On the other hand, private expenditures could behave countercyclically, because economic downturns affect people's mental health, in the form of increased anxiety about the future (McInerney and Mellor 2012). Therefore, they might increase their spending in the mental health sector. People who are at risk of losing their jobs also experience increased health risks (Deb et al. 2011; Tefft 2011). This group grows larger when the economy declines, so treatment costs may increase overall.

Because these arguments suggest a wide range of possible outcomes with regard to the business-cycle sensitivity of public and private healthcare expenditures, we expect substantial cross-country variability in private and public cyclical sensitivities.

\section{Method}

We derive cyclical comovement elasticities, which quantify the cyclical sensitivity of public and private healthcare expenditures separately for each country under investigation. We first filter out fluctuations that correspond to business-cycle periodicities. Next, we relate cyclical 
fluctuations in private (public) healthcare expenditures to those of the economy as a whole, which reveals the private (public) comovement elasticities. ${ }^{2}$

Extracting the cyclical component. We use the well-known Hodrick and Prescott (HP) (1997) filter to extract the cyclical component from series of public and private healthcare expenditures (see Lamey et al. 2007 for a detailed review of the HP Filter). The HP filter decomposes a time series $\left(y_{t}\right)$ into a steadily evolving long-term trend component $\left(y_{t}^{\text {trend }}\right)$ and a cyclical component $\left(y_{t}^{c}\right)$, which fluctuates around the long-term trend. It extracts the trend component $y_{t}^{\text {trend }}$ of a time series by minimizing the following specification:

$$
\sum_{t=1}^{T}\left(y_{t}-y_{t}^{\text {trend }}\right)^{2}+\lambda \sum_{t=2}^{T-1}\left(\left(y_{(t+1)}^{\text {trend }}-y_{t}^{\text {trend }}\right)-\left(y_{t}^{\text {trend }}-y_{(t-1)}^{\text {trend }}\right)\right)^{2}
$$

where $\mathrm{T}$ represents the number of years included in the time series. The first quadratic term is a goodness-of-fit measure; the second quadratic expression determines the smoothness of the trend component. The solution to specification (1) thus represents a trade-off between fit and smoothness, based on the smoothing parameter $\lambda$ (Hodrick and Prescott 1997). The larger the value of $\lambda$, the smoother the trend component is. We set the smoothing parameter to equal 10 , a value that produces a good correspondence between the HP filter and an ideal band-bass filter that passes through cycles between two an eight years (i.e., business-cycle periodicities) (Baxter and King 1999). To obtain the cyclical component $\left(y_{t}^{c}\right)$, we remove the long-term component $\left(y_{t}^{\text {trend }}\right)$ from the original series $\left(y_{t}\right)$ :

\footnotetext{
${ }^{2}$ A simultaneous derivation of the cyclical component of the time series and quantification of the comovement elasticity and/or long-run effects (Section 3) would be prohibitively complicated. In line with prior studies (e.g., Lamey et al. 2007, 2012; Steenkamp and Fang 2011) and for exposition, we use a multi-stage approach. An alternative might estimate a single, fully flexible (potentially non-linear) model, which would decrease the efficiency loss due to our multi-stage estimation.
} 


$$
y_{t}^{c}=y_{t}-y_{t}^{\text {trend }}
$$

Because we are interested in the per-country sensitivity of public and private healthcare expenditures, we apply this procedure to the healthcare expenditures time series $\left(\right.$ hce $\left._{\text {ist }}\right)$ of each country $i$, expenditure source $s$ (i.e., public $[p u b]$ or private [pri]), and time period $t$ to obtain the cyclical component $\left(\right.$ hce $\left._{\text {ist }}^{c}\right)$.

Relating the cyclical component to the business cycle. To measure the relationship between healthcare expenditures and the aggregate business cycle, we computed the cyclical comovement elasticity (see e.g. Lamey et al. 2007 for a similar practice). This comovement elasticity measures how cyclical fluctuations in the aggregate economy translate into cyclical fluctuations in private (public) healthcare expenditures. It is obtained by regressing the cyclical component of healthcare expenditures $\left(h c e_{i s t}^{c}\right)$ on the cyclical component of GDP $\left(g d p_{i t}^{c}\right)$ on a per-country base (see Equation 3). The cyclical component of GDP $\left(g d p_{i t}^{c}\right)$, obtained via the HP-filter (following Equations 1 and 2), includes the business cycle fluctuations across many industries on a national level and is thus an appropriate indicator of the business cycle. Accordingly,

$$
h c e_{i s t}^{c}=\beta_{i s} g d p_{i t}^{c}+\varepsilon_{i s t}
$$

To enhance comparability, both series were log-transformed before filtering, to represent percentage deviations from a long-term trend. Therefore, $\beta_{i s}$ can be interpreted as a comovement elasticity. The sign of the elasticity indicates whether a country's public or private healthcare expenditures are procyclical $\left(\beta_{i s}>0\right)$ (i.e., increase during expansions and decrease during contractions) or countercyclical $\left(\beta_{i s}<0\right)$ (i.e., decrease during expansions and 
increase during contractions). To control for potential autocorrelation, we allow for an autoregressive (AR) error term in Equation 3 (see Lamey et al. 2012). Whether an AR term is included depends on the Akaike information criterion.

\section{Data}

The data set covers the public and private healthcare expenditures of 32 OECD countries between 1990 and 2011. ${ }^{3}$ To capture multiple business cycles, we selected all OECD countries with at least 13 subsequent observations within this time frame, producing an average of 20 subsequent observations per country (see e.g. Lamey et al., 2007 and van Heerde et al. 2013 for a similar practice). Table 1 contains an overview of our key measures.

-- insert Table 1 about here--

Annual public and private healthcare expenditures, measured in national currency, came from the OECD’s Health Data 2013, which is the most complete source of differentiated data on healthcare expenditures. All data are in constant year 2005 terms, measured on a per capita basis. Private healthcare expenditures refer to the combined expenditures of all privately funded sources, such as private insurance payments and out-of pocket or copayments for treatments or medication by consumers. Public healthcare expenditures include both general and regional government expenditures, financed with tax revenues or social security funds. Finally, we gathered data on GDP per capita in constant 2005 prices (in national currencies) from the OECD Economic Indicator database.

\footnotetext{
${ }^{3}$ To ensure our cross-sectional analyses in steps 2 and 3 rely on comparable time windows, we disregarded the observations available prior to 1990 for a few countries in our sample.
} 


\section{Findings}

We ranked the estimated comovement elasticities of public and private healthcare expenditures. Figure 1 shows the mean elasticity per quartile for these ranked estimated comovement elasticities.

--- insert Figure 1 about here---

The sign of the elasticity indicates whether healthcare expenditures behave procyclically $(+)$ and move in the same direction as the economy or countercyclically (-) and move in the opposite direction. As we expected, Figure 1 reveals great diversity in the comovement elasticities across both countries and spending source (i.e., private versus public). A metaanalysis, obtained by the method of adding weighted Zs (Rosenthal 1991), shows that private spending on average is procyclical $(Z=2.23 ; p<.05)$. However, we find no unidirectional effect of business cycle sensitivity in the public comovement elasticities $(Z=-.359 ; p>.1)$.

We also consider whether the elasticities of public and private expenditures within a country tend to move in the same direction (Table 2). More than one-third of all countries in the sample (37.5\%) display procyclical private and public healthcare expenditures; another $25 \%$ shows purely countercyclical behavior. In the latter situation, both private and public buyers invest consistently during an economic crisis, but the two types of buyers exhibit opposite reactions in the former case. Although somewhat less frequently, private and public expenditures may also exhibit contrary directions: in $12.5 \%$ (25\%) of the cases, tough economic times prompt private consumers to spend consistently more (less) on healthcare, while the government uses the opportunity to save (spend) money in this sector.

--- insert Table 2 about here--- 


\section{LONG-TERM CONSEQUENCES OF CYCLICAL SENSITIVITY}

Having established the cyclical sensitivity of the healthcare sector in section 2, we now turn to the long-term impact of this cyclical sensitivity on mortality rates and total healthcare spending. Temporal cuts in healthcare spending might both inflate and deflate the mortality rate in the long run, depending on the source of the budget cuts. If certain diseases (e.g., HIV, schizophrenia, visual impairment) are not treated promptly, due to private budget cuts, they may cause irreversible harm to patients, which might lead to a long-term increase in the mortality rate (Hitris and Posnett 1992). Yet, public cuts in the health sector may be required at regular times to ensure its efficiency (see the Canadian example discussed in Liu et al. 2001), and these cuts are easier to justify when the overall economy is struggling (Lane 2003b). In addition, Ruhm (2000, 2003, 2005) shows that mortality rates tend to decrease during economic recessions (i.e., procyclical pattern), ${ }^{4}$ indicating that cuts in health expenditures during tough economic times are sensible. When public cost cuts during economic downturns indeed lead to increased efficiency in the sector, they may deflate the mortality rate of the overall population.

More efficient healthcare systems also cost less money, implying that efficient public cost cuts during tough economic times should lead to lower long-term growth in healthcare expenditures. In contrast, private cost cuts during these periods may require subsequent overcompensation to regain the same level of healthcare that the person enjoyed prior to the reductions (Blanchard and Summers 1986; Fatás 2002). Procyclical reductions of private healthcare expenditures also might results in the postponement of less urgent treatments (Strine et al. 2008), which could increase the chances of extremely costly, urgent procedures later and thereby inflate overall health expenditures in the long run.

\footnotetext{
${ }^{4}$ In a more recent study, Ruhm (2013) finds that the cyclical sensitivity of mortality has grown more dependent on the cause of death. Deaths due to cardiovascular diseases and vehicle accidents remain procyclical; deaths caused by cancer have become countercyclical since 2010. Our observation window ends in 2011, so we assume that the mortality rate has behaved procyclically for most of our observation window.
} 


\section{Method}

To measure the long-term consequences of cyclical sensitivity, we link the comovement elasticities of healthcare expenditures to long-term average growth in the mortality rate (Equation 4) and total healthcare expenditures (Equation 5):

$$
\begin{aligned}
& \overline{\Delta \text { mortality }{ }_{i}^{\text {trend }}}=\gamma_{0}+\gamma_{1} \hat{\beta}_{\text {ipub }}+\gamma_{2} \hat{\beta}_{\text {ipri }}+\gamma_{3} \overline{\Delta h c e_{i}^{\text {trend }}}+\vartheta_{i} \\
& \overline{\Delta h c e_{i}^{\text {trend }}}=\delta_{0}+\delta_{1} \hat{\beta}_{\text {ipub }}+\delta_{2} \hat{\beta}_{\text {ipri }}+\delta_{3} \overline{\Delta g d p_{i}^{\text {trend }}}+\varkappa_{i}
\end{aligned}
$$

Mortality trend $^{\text {trend }}$ hce $e_{i t}^{\text {trend }}$ are the long-term components of the mortality rate and total healthcare expenditures series, respectively, for country i derived through the HP filter (Equation 1). We capture long-term growth by focusing on the average yearly growth rates of these series (i.e., $\overline{\Delta m o r t a l i t y}{ }_{i}^{\text {trend }}$ and $\overline{\Delta h c e_{i}^{\text {trend }}}$ ), estimated by an intercept-only regression on the first differences of the log-transformed trend components.

As past research has shown that the mortality rate relates to healthcare expenditures in the long run (see e.g. Hitiris and Posnett 1992), we included the long-term average growth of total healthcare expenditures $\left(\overline{\Delta h c e_{i}^{\text {trend }}}\right)$ as a control variable in Equation 4. In Equation 5, we also control for long-term average growth of GDP $\left(\overline{\Delta g d p_{i}^{\text {trend }}}\right)$ as GDP is the most influential factor driving long-term healthcare expenditure growth (Barros 1998; Di Matteo and Di Matteo 1998). This specification yields simultaneity, for which we control by applying a two-stage least squares procedure in Equation 4. The long-term GDP growth is an instrument for the endogenous long-term growth of healthcare expenditures (Gerdtham and Loethgren 2000). The Cragg-Donald test statistic was significant $(\mathrm{F}(1,22)=7.40, p<.10)$, so our instrument demonstrates sufficient strength. 
The dependent variables in Equations 4 and 5 are estimated values, with varying degrees of estimation accuracy. To control for potential biases in the standard error estimates, we used the inverse of the standard errors of the long-term average growth rates as weights in our estimation. In addition, we divided the estimated comovement elasticities on the righthand sides of Equations 4 and 5 by their standard errors, to control for estimation biases (see Pauwels and Hanssens 2007 for a similar practice).

\section{Data}

We obtained the per country data about the standardized number of deaths (due to internal causes) per 100,000 inhabitants per year from the OECD. This variable is comparable across countries, because it controls for differences in age structures (OECD 2011). Dynamics in this value thus depict pure gains or losses in the health of a country's population. The data on healthcare expenditures and GDP came from the OECD statistics, as we described in Section 2, and the descriptives of the variables are in Table 1.

\section{Findings}

We summarize the results in Table 3. Public comovement elasticity has a significant, negative effect on the average long-term growth of mortality $\left(\gamma_{\widehat{\beta}_{\text {ipub }}}=-.0014 ; p<.05\right)$. Countries with greater procyclical sensitivity in public healthcare expenditures thus exhibit a lower long-term growth rate in mortality. However, we find no significant effect for the private comovement elasticity $\left(\gamma_{\widehat{\beta}_{i p r i}}=-.0002 ; p>.10\right)$. We also uncover a negative relationship between the average long-term growth in total healthcare expenditures and average long-term growth in mortality $\left(\gamma \frac{\widehat{\Delta h c_{i}^{\text {trend }}}}{2}=-.2886 ; p<.10\right)$, in line with Hitris and Posnett’s (1992) findings. 
Although long-term growth in the mortality rate depends on the cyclical sensitivity of public healthcare expenditures, long-term growth in total healthcare expenditures instead is driven by the cyclical sensitivity of the private healthcare investments. Private comovement elasticity has a significant positive impact on the average long-term growth of total healthcare expenditures $\left(\delta_{\widehat{\beta}_{i p r i}}=.0019 ; p<.01\right)$. Public comovement elasticity, in contrast, does not have any impact on the long-term growth in total healthcare expenditures $\left(\delta_{\widehat{\beta}_{i p u b}}=.0003 ; p>.10\right)$. Finally, in line with Herwartz and Theilen (2003), we find that GDP growth has a significant positive impact on average growth in total healthcare expenditures $\left(\delta \frac{}{\Delta g d p_{i}^{\text {trend }}}=.9683 ; p<\right.$ $.01)$.

\section{Discussion}

Procyclical fluctuations in public health expenditures drive down the growth in the mortality rate. Consistently cutting public health expenditures during an economic contraction (i.e., a procyclical strategy) improves the long-term health status of the population more than consistently decreasing public spending in the health sector during economic upturns (i.e., a countercyclical strategy). Reductions in healthcare expenditures at regular times are necessary to make the healthcare sector more efficient. An economic downturn appears to offer the perfect opportunity to do so, because such cuts are easier to justify in tough economic climates (Lane 2003b). Moreover, as the rich literature stream led by Ruhm (2000, 2003, 2005) has shown, mortality rates tend to be lower in economic downturns. When cutting public health expenditures is necessary for efficiency reasons, it also makes sense to do so when the general population's health status tends to be better, namely in periods of economic contractions. Cyclical sensitivity in private healthcare expenditures has no significant impact on long-term mortality rates. 
Instead, the business cycle volatility of private expenditures influences long-term growth in total healthcare expenditures. When private consumers decide to economize on healthcare provisions during tough economic times, they postpone both urgent and less urgent treatments, which increases their likely need for extremely costly, urgent procedures later (OECD 2011).

\section{EXPLANATORY FACTORS FOR CYCLICAL SENSITIVITY}

In the previous analyses, we demonstrated the variance of cyclical sensitivity in public and private healthcare expenditures, as well as their long-term consequences. In this section, we investigate policy decisions that may explain such cross-country variability.

Extent of private healthcare funding. Systems with more private expenditures allocate increased responsibility to individual consumers (Glied 2008), which reduces opportunities for collectivistic risk pooling. During an economic contraction, fewer people can afford care, which might cause private expenditures to be more procyclical. Furthermore, in predominantly private healthcare systems, the state has a small role in healthcare provision, which makes it easier for politicians to economize on the healthcare budget when economic times are tight (Glied 2008). This element might result in higher procyclical fluctuations of public expenditures.

Social health insurance based healthcare system. A public healthcare budget might be collected by taxes (Beveridge system) or social health insurances (Bismarck system) collected from the workforce. During economic downturns, the revenues from social health insurances decrease, because of the higher unemployment rate. Tax-related systems instead draw revenues from both taxes and nontax government revenues (Wagstaff 2009), which are less sensitive to the business cycle, in that they get collected from less cyclical sources (Glied 
2008). Therefore, we expect public healthcare expenditures to be more procyclical in countries in which the public healthcare budget relies on social health insurance revenues. ${ }^{5}$

Public prevention budgets. Governments invest in prevention activities to improve their citizens' health consciousness and the timely acquisition of treatments or preventive actions (OECD 2011). Such prevention campaigns increase health awareness, which might induce more stable health expenditures. That is, we expect that a higher level of public prevention expenditures decreases the procyclical sensitivity of private healthcare expenditures.

Public debt. Countries with a stronger fiscal position suffer less severely in economic downturns (Berkmen et al. 2012). Nations with a lower debt level have fewer obligations, so they have more room to maneuver during economic downturns. Therefore, we expect public health expenditures to be less procyclical in countries with lower debt levels.

\section{Method}

To identify the explanatory factors of cyclical sensitivity, we regressed the private and public comovement elasticities on the previously outlined factors in a system of Equations 6 and 7:

$$
\begin{gathered}
\hat{\beta}_{\text {ipri }}=\zeta_{0}+\zeta_{1} \overline{\text { Extent of private funding }_{i}}+\zeta_{2} \overline{\text { Prevention budget }_{i}}+\phi_{i} \\
\hat{\beta}_{\text {ipub }}=\eta_{0}+\eta_{1} \overline{\text { Extent of private funding }} i \\
+\eta_{3} \overline{\text { Debt }_{i}}+\varrho_{i}
\end{gathered}
$$

\footnotetext{
${ }^{5}$ The cyclicality of a country's revenues may also depend on their dependency on natural resources because of fluctuating commodity prices. We tested whether countries whose export relied more on natural resources have a higher business cyclicality of the healthcare sector in an extra analysis. In line with Sachs and Warner (1997), we operationalize this dependency as the extent of export that comes from primary products and natural resources, derived from the UN Comtrade database. However, a country's dependency on natural resources turns out to be unrelated to the cyclical sensitivity of both private and public health care expenditures, and therefore we decided to not include it in our final model. We thank an anonymous reviewer for this suggestion.
} 
$\overline{\text { Extent of private funding }}$ represents the average degree to which a healthcare system is private, and Social health insurance system $i$ indicates whether the healthcare system is financed by social health insurance (rather than taxes). We also account for the average extent of preventive budgets relative to GDP $\overline{\text { Prevention budget }_{i}}$, whereas $\overline{\text { Debt }_{i}}$ indicates the average degree of public debt relative to GDP.

The dependent variables, the comovement elasticities derived from Equation 3, are estimated values with differing degrees of estimation accuracy, so we used the standard errors as weights in the estimation. Finally, we allowed for correlation between the error terms $\phi_{i}$ and $\varrho_{i}$ by estimating Equations 6 and 7 as a system, using seemingly unrelated regression.

\section{Data}

The extent of private funding is operationalized as the average ratio of private expenditures and total health expenditures over time. We account for a social health insurance system by a dummy variable that equals 1 for a health system that is financed by social health insurance funds and 0 for systems financed by taxes (classification adopted from Wagstaff 2009). The prevention budget is the average annual public prevention spending relative to GDP during our research period, and debt is operationalized as the average public debt relative to GDP. We determined public debt from the OECD economic indicator database; all other variables came from the OECD Health Data 2012. The descriptives of these variables are included in Table 1.

\section{Findings}

As we show in Table 4, the share of private expenditures related positively to cyclical fluctuations in private healthcare expenditures $\left(\zeta \frac{}{\text { Extent of private funding }}=1.423 ; p<.05\right)$, whereas higher levels of prevention expenditures related negatively to the private 
comovement elasticities $\left(\zeta \overline{\text { Prevention budget }_{i}}=-93.005 ; p<.10\right)$. For the comovement elasticities of public expenditures (Equation 7), a different picture emerged though. When countries' healthcare systems rely on social health insurance, they tend to show more procyclical sensitivity to the business cycle than do countries with tax-based systems $\left(\eta_{\text {Social health insurance system }_{i}}=0.370 ; \mathrm{p}<.05\right)$. We found no significant effects of the extent of private healthcare expenditures ( $\left.\eta_{\text {Extent of private funding }}=-.755 ; \mathrm{p}>.10\right)$ and the country’s average debt level $\left(\eta \frac{}{\overline{D e b t}_{i}}=-.0004 ; \mathrm{p}>.10\right)$.

--- insert Table 4 about here---

\section{Discussion}

The business cycle volatility of private healthcare expenditures is driven by the extent of private funding in the healthcare sector and the extent of a public prevention budget. In healthcare systems with greater private expenditures, the responsibility of healthcare shifts to the consumers (Glied 2008), and the opportunities for collectivistic pooling diminish. Therefore, private healthcare expenditures depend heavily on individual budgets available for health care. Because average consumer budgets tend to be lower in tough economic times, countries that depend more on private expenditures in the health sector tend to be more procyclical.

The results also show that the government has important means at its disposal to reduce this procyclical behavior by private buyers. Countries with higher prevention budgets successful mitigate cost cutting by private consumers during economic downturns. By investing in prevention activities, governments can increase the population's health awareness and consciousness (OECD 2011), which encourages people to refrain from cutting back on their healthcare during economic contractions. 
On the public side of healthcare expenditures, a different picture emerges. The extents of private funding and debt have no significant effects on the business cycle sensitivity of public healthcare expenditures, but the manner in which the public healthcare budget gets collected matters. Countries that mainly rely on a Bismarck system and collect funding from the workforce through social health insurance, tend to be more procyclical than countries with tax-based (or Beveridge) systems. This finding is not surprising; social health insurance gets collected from workforce sources that are much more sensitive to business cycles than are general taxes (Glied 2008).

\section{CONCLUSION}

By examining the business cycle sensitivity of public and private healthcare expenditures in 32 countries, we find enormous diversity in how public and private healthcare spending relate to the business cycle. Private buyers in $62.5 \%$ of these countries economize on their healthcare expenditures during economic contractions, such that by switching to less expensive generic pharmaceuticals and postponing less urgent medical treatments (Deloitte 2011). Yet, private healthcare expenditures instead move in the opposite direction of the economic business cycle in $37.5 \%$ of the countries in our sample. Economic contractions can lead to increases in the rates of some diseases (Stuckler et al. 2009), which might explain this increase in private healthcare spending during tough economic times. For the public component of healthcare expenditures, we find similar diversity across countries. Half of the governments consistently spend more during economic downturns, following a classical Keynesian approach that seeks to stimulate the economy by increasing public spending on healthcare when the economy stumbles (Lane 2003a). The other half appear to follow the opposite strategy, such that when their economy goes sour, these governments feel forced to 
reduce their expenditures (Berkmen et al. 2012). An economic contraction even can offer a justification for reorganizing the socially delicate healthcare sector (Lane 2003b).

In addition to these necessary insights into the cyclical sensitivity of healthcare expenditures, our study seeks to help policy makers establish the consequences of different strategies in the long term. We find that economizing on private expenditures during economic crises increases growth in total healthcare expenditures. By eliminating preventive treatment or postponing less urgent medical procedures, consumers might let diseases grow unchecked and thus face more expensive treatments later. Policy makers need to discourage such postponement behavior, whether by educating people about the underlying risk or temporarily reducing the out-of-pocket payments they require. In contrast, procyclical behavior on the public side leads to more negative growth in the country's mortality figures overall. Governments thus should leverage tough economic environments to justify budget cuts in the healthcare sector, necessary to increase its efficiency, because ultimately they help improve the health status of the population.

Finally, we provide insights into which factors influence the degree of cyclical sensitivity. Public prevention activities and a publicly funded healthcare system reduce the procyclical volatility of private healthcare expenditures. Considering the negative long-term consequences in terms of total healthcare expenditures, these findings suggest a stronger emphasis on prevention in line with recent OECD recommendations (Gurria 2011). In addition, our findings lend support to proponents of initiatives to broaden public healthcare systems, such as the U.S. Affordable Healthcare Act (popularly known as Obamacare). Systems that rely more on social health insurance sources have more procyclical public expenditures, which deflate the mortality rate. Therefore, it appears beneficial to move from pure tax-based systems toward social health insurance systems. 
In summary, this article contributes to the ongoing discussion about how to maintain the population's health status (low mortality rates) while also keeping healthcare expenditures under control. We show that, beyond the generally accepted role of GDP, cyclical behaviors by public and private parties in the healthcare sector have important impacts in the long run. Countries should seek to minimize budget cuts by private citizens but stimulate public budget cuts during economic contractions, by increasing prevention activities and reformulating their healthcare as a more publicly funded system that relies predominantly on social insurances. 


\begin{tabular}{|c|c|c|c|c|c|}
\hline Series & Mean & SD & Min & Max & $\mathrm{N}$ \\
\hline \multicolumn{6}{|l|}{ Healthcare Expenditures } \\
\hline $\begin{array}{l}\text { Average per-country private } \\
\text { healthcare expenditures } \\
\text { relative to GDP (in\%) }\end{array}$ & 2.33 & 1.30 & 0.70 & 7.95 & 32 \\
\hline $\begin{array}{l}\text { Average per-country public } \\
\text { healthcare expenditures } \\
\text { relative to GDP (in \%) }\end{array}$ & 5.79 & 1.50 & 2.39 & 8.20 & 32 \\
\hline \multicolumn{6}{|l|}{ Long-Term Consequences } \\
\hline $\begin{array}{l}\text { Average per-country growth } \\
\text { in number of deaths*(in \%) }\end{array}$ & -2.59 & 0.53 & -4.05 & -1.67 & 31 \\
\hline $\begin{array}{l}\text { Average per-country growth } \\
\text { in total health expenditures } \\
\text { (in \%) }\end{array}$ & 3.34 & 1.31 & 1.60 & 7.60 & 32 \\
\hline
\end{tabular}

\section{Average per-country proportion of private} healthcare expenditures in total healthcare expenditures

$$
\text { (in \%) }
$$

Social health insurance

$$
\text { system (0/1) }
$$

0.44

0.50

0

1

32

Average per-country prevention expenditures relative to GDP**

Average per-country public $47.80 \quad 28.50$ 
Table 2: Distribution of comovement elasticities

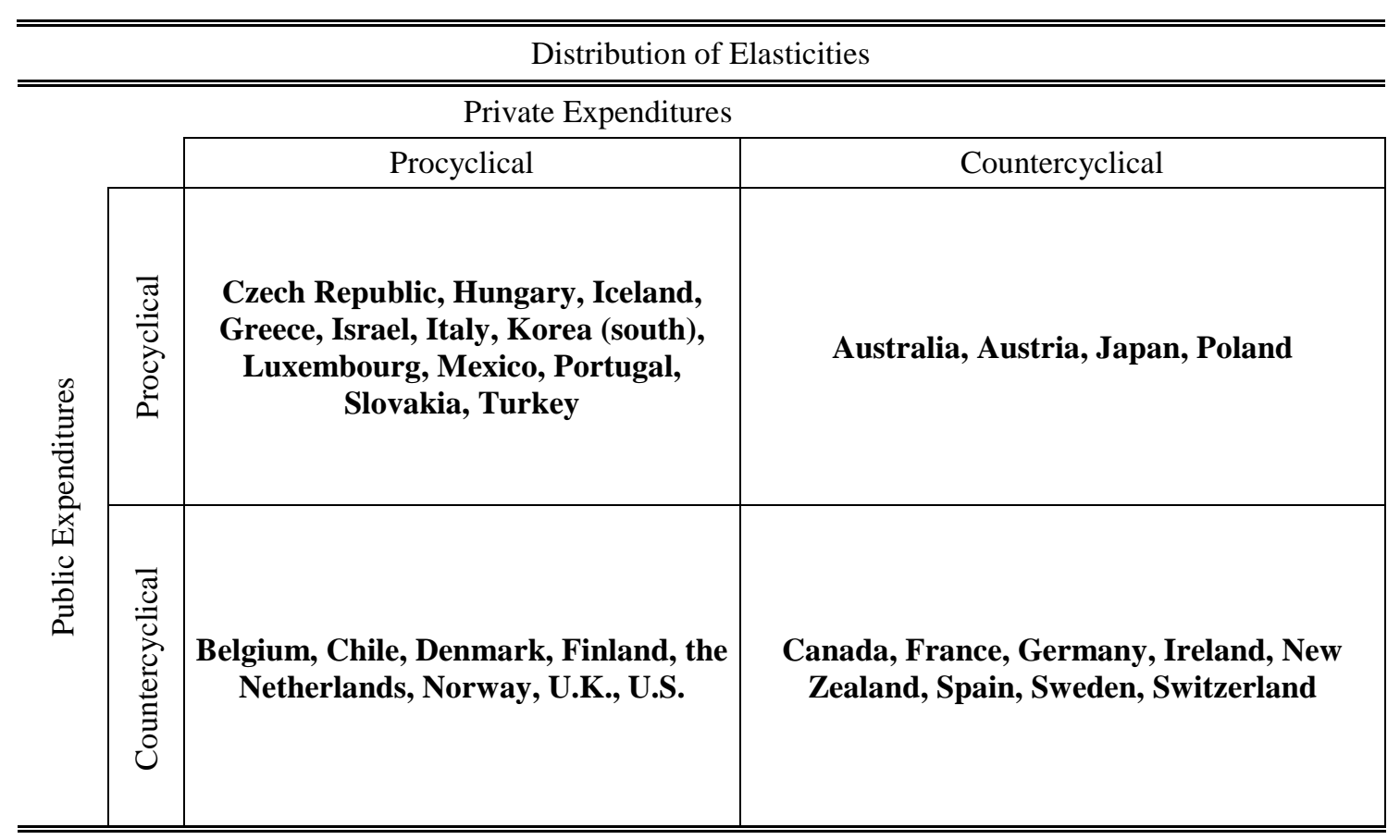


Table 3: Long-term consequences of cyclical sensitivity

\begin{tabular}{|c|c|c|c|c|c|c|c|c|}
\hline \multicolumn{3}{|c|}{$\overline{\text { Dependent variable : } \Delta \text { mortality }_{i}^{\text {trend }}}$} & \multirow{2}{*}{$\begin{array}{c}\mathrm{n}=31 \\
\text { St Error }\end{array}$} & \multicolumn{3}{|c|}{ Dependent variable: $\overline{\Delta \text { hce }_{i}^{\text {trend }}}$} & \multicolumn{2}{|c|}{$\mathrm{n}=32$} \\
\hline Independent Variable & Coefficient & & & Independent Variable & Coefficient & & St & Error \\
\hline Intercept & -0.0157 & $* * *$ & 0.0050 & Intercept & 0.0165 & $* * *$ & & 0.0020 \\
\hline$\hat{\beta}_{\text {ipri }}$ & -0.0002 & & 0.0007 & $\hat{\beta}_{\text {ipri }}$ & 0.0019 & $* * *$ & & 0.0006 \\
\hline$\hat{\beta}_{\text {ipub }}$ & -0.0014 & $* *$ & 0.0005 & $\hat{\beta}_{i p u b}$ & 0.0003 & & & 0.0007 \\
\hline$\overline{\Delta \text { hce }_{i}^{\text {trend }}}$ & -0.2886 & $*$ & 0.1675 & $\overline{\operatorname{gdp}_{i}^{\text {trend }}}$ & 0.9683 & $* * *$ & & 0.1032 \\
\hline $\mathrm{R}^{2}$ & & $.52 \%$ & & $\mathrm{R}^{2}$ & & $1.62 \%$ & & \\
\hline
\end{tabular}

Table 4: Explanatory factors of cyclical sensitivity

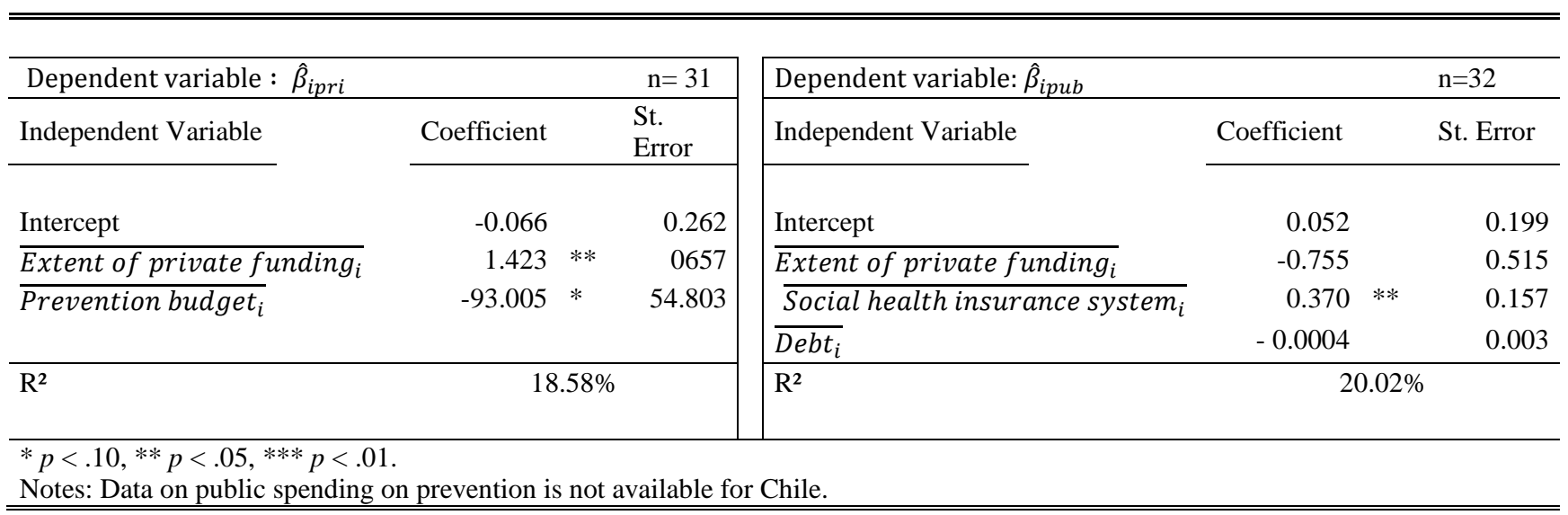


Figure 1: Average quartile values of the comovement elasticities

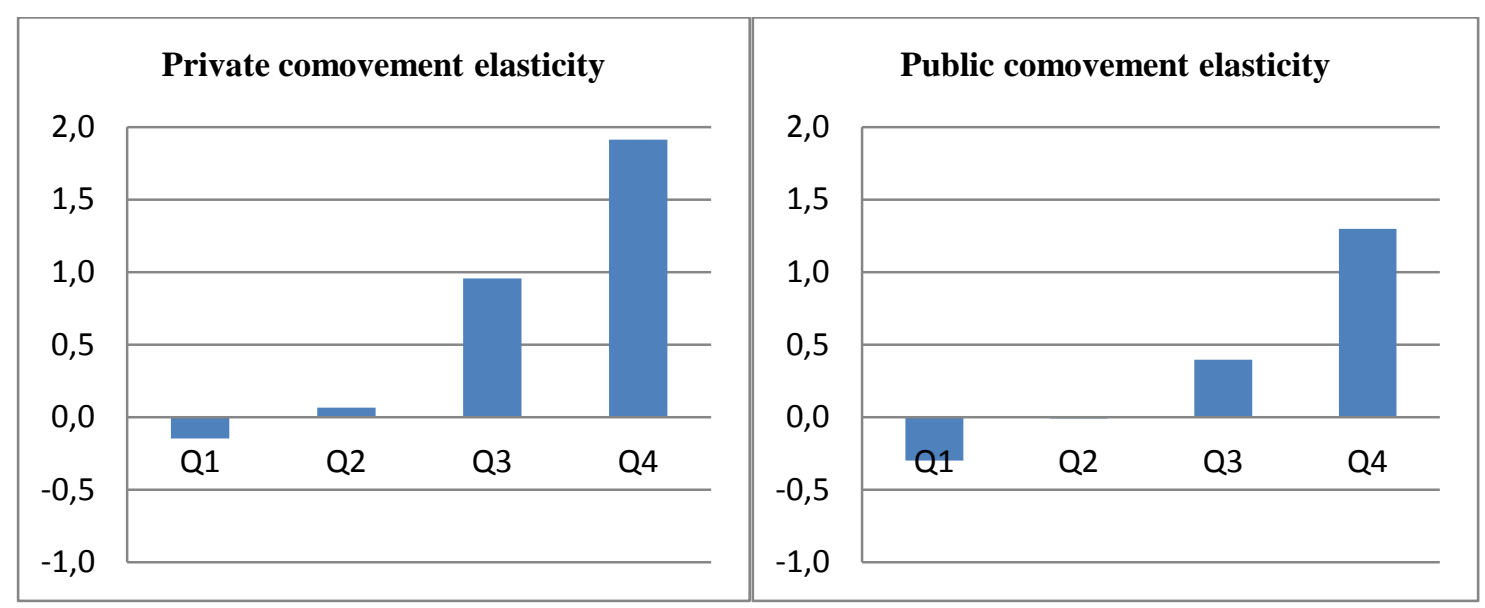




\section{REFERENCES}

Barros, P. P. (1998) 'The black box of health care expenditure growth determinants', Health Economics, 7, 533-544.

Baxter, M. (1994) 'Real exchange rates and real interest differentials. Have we missed the business cycle relationship?', Journal of Monetary Economics, 33(1), 5-37.

Baxter, M. and King, R. G. (1999) 'Measuring business cycles: approximate band-pass filters for economic time series', Review of Economics and Statistics, 81(4), 575-593.

Berkmen, S. P., Gelos, G., Rennhack, R. and Walsh, J. P. (2012) 'The global financial crisis: Explaining cross-country differences in the output impact', Journal of International Money and Finance, 31(1), 42-59.

Blanchard, O. J. and Summers, L. H., eds. (1986) Hysteresis and the European unemployment problem, MIT Press.

Blomqvist, A. G. and Carter, R. A. L. (1997) 'Is health care really a luxury', Journal of Health Economics, 16, 207-229.

Clemente, J., Marcuello, C., Montanes, A. and Pueyo, F. (2004) 'On the international stability of health care expenditure functions: are government and private functions similar?', Journal of Health Economics, 23, 589-613.

Deb, P., Gallo, W. T., Ayyagari, P., Fletcher, J. M. and Sindelar, J. L. (2011) 'The effect of job loss on overweight and drinking', Journal of Health Economics, 30(2), 317-327.

Deloitte (2011) '2011 U.S. and Global Survey of Health Care Consumers', [online], available: http://www.deloitte.com/us/2011consumerism [accessed 06.03.2013].

Di Matteo, L. and Di Matteo, R. (1998) 'Evidence on the determinants of Canadian provincial government health expenditures: 1965-1991', Journal of Health Economics, 17(2), 211-228.

Fatás, A. (2002), “The effects of business cycles on growth,” in Economic Growth: Sources, Trends and Cycles, Norman Loayza and Raimundo Soto, eds. Central Bank of Chile, 191-219. 
Gerdtham , U.-G. and Jönsson, B. (2000) 'International comparisons of health expedniture: theory, data and econometric analysis' In: Hanbook of Health Economics, Volume 1, A.J. Culyer and J.P. Newhouse (eds.), Elsevier: Amsterdam (NL).

Gerdtham, U.-G. and Loethgren, M. (2000) 'On stationarity and cointegration of international health expendidure and GDP', Journal of Health Economics, 19, 461-475.

Gerdtham, U.-G. and C.J. Ruhm (2006) 'Death rise in good economic times: evidence from the OECD', Economics and Human Biology, 4, 298-316.

Getzen, T. E. (2000) 'Health care is an individual necessity and a national luxury: Applying multilevel decision models to the analysis of health care ', Journal of Health Economics, 19, 259-270.

Glied, S. A. (2008) 'Health Care Financing, Efficiency, and Equity', NBER, No. 13881.

Gurria, A. (2011) 'Healthcare and the value of prevention', [online], available: http://www.oecdobserver.org/news/fullstory.php/aid/3318/Healthcare_and the_value of_prevention.html [accessed 06.12.2012].

Hansen, P. and King, A. (1996) 'The determinants of health care expenditure: A cointegration approach', Journal of Health Economics, 15, 127-137.

Herwartz, H. and Theilen, B. (2003) 'The determinants of health care expenditure: testing pooling restrictions in small samples', Health Economics, 12(2), 113-124.

Hitiris, T. and Posnett, J. (1992) 'The determinants and effects of health expenditure in developed countries', Journal of Health Economics, 11, 173-181.

Hodrick, R. J. and Prescott, E. C. (1997) 'Postwar U.S. business cycles: an empirical investigation', Journal of Money, Credit \& Banking, 29(1), 1-16.

Katona, G. (1974) 'Psychology and consumer economics', Journal of Consumer Research, 1(1), 1-8.

Lamey, L., Deleersnyder, B., Dekimpe, M. G. and Steenkamp, J.-B. E. M. (2007) 'How business cycles contribute to private-label success: evidence from the United States and Europe', Journal of Marketing, 71(1), 1-15. 
Lamey, L., Deleersnyder, B., Steenkamp, J-B. E.M., Dekimpe M.G. (2012) 'The effect of business cycle fluctuations on private-label share: what has marketing conduct got to do with it', Journal of Marketing, 76 (1), 1-19.

Lane, P. R. (2003a) 'Business cycles and macroeconomic policy in emerging market economies', International Finance, 6(1), 89-108.

Lane, P. R. (2003b) 'The cyclical behaviour of fiscal policy: evidence from the OECD', Journal of Public Economics, 87(12), 2661-2675.

Liu, L., Hader, J., Brossart, B., White, R. and Lewis S. (2001) 'Impact of rural hospital closures in Saskatchewan, Canada’, Social Science \& Medicine,52, 1793-1804.

McCoskey, S. K. and Selden, T. M. (1998) 'Health care expenditures and GDP: panel data unit root test results', Journal of Health Economics, 17, 369-76.

McInerney, M. and Mellor, J. M. (2012) 'Recessions and seniors' health, health behaviors, and healthcare use: Analysis of the Medicare Current Beneficiary Survey', Journal of Health Economics, 31(5), 744-751.

Miller, D., M.E. Page, A.H. Stevens, and M. Filipski (2009) 'Why are recessions good for your health' American Economic Review, 99 (2), 122-127.

Mladovsky, P., Srivastava, D., Cylus, J., Karanikolos, M., Evetovits, T., Thomson, S. and McKee, M. (2012) 'Health policy responses to the financial crisis in Europe', WHO Policy Summary number 5.

Narayan, P. K. and Narayan, S. (2008) 'The role of permanent and transitory shocks in explaining international health expenditures', Health Economics, 17 10, 1171-86.

Neumayer, E. (2004) 'Recessions lower (some) mortality rates: Evidence from Germany', Social Science and Medicine, 58(1037-1047).

Newhouse, J. P. (1977) 'Cross national differences in health spending: what do they mean?', Journal of Health Economics, 6, 159-162.

OECD (2011) 'Health at a Glance 2011: OECD Indicators', OECD Publishing.

Pauwels, K. and D. M. Hanssens (2007) 'Performance regimes and marketing policy shifts', Marketing Science, 26 (3), 293-311. 
Ruhm, C.J. (2000) 'Are recessions good for your health?', Quarterly Journal of Economics, 115 (2), 617-650.

Ruhm, C.J. (2003) "Good times makes you sick', Journal of Health Economics, 24 (4), 637658.

Ruhm, C.J. (2005) 'Mortality increases during economic upturns', International Journal of Epidemiology, 34 (6), 1206-1211.

Ruhm, C.J. (2013) 'Recessions, healthy no more?', Wokring Paper.

Rosenthal, R. (1991) Meta-analytic procedures for social research, Newbury Park: Sage.

Sachs, Jeffrey D. and Andrew M. Warner (1997), 'Natural resource abundance and economic growth’, Harvard University Working Paper.

Steenkamp, J.-B. E.M. and E. Fang (2011), "The impact of economic contractions on the effectiveness of R\&D and advertising: evidence from U.S. companies spanning three decades," Marketing Science, 30(4), 628-645.

Strine, T. W., Chapman, D. P., Balluz, L. S., Moriarty, D. G. and Mokdad, A. H. (2008) 'The associations between life satisfaction and health-related quality of life, chronic illness, and health behaviors among US community-dwelling adults', Journal of community health, 33(1), 40-50.

Stuckler, D., Basu, S., Suhrcke, M., Coutts, A. and McKee, M. (2009) 'The public health effect of economic crises and altermative poliocy responses in Europe: An empirical analysis', Lancet, 374(July), 315-323.

Tefft, N. (2011) 'Insights on unemployment, unemployment insurance, and mental health', Journal of Health Economics, 30(2), 258-264.

Thorlby, R. (2011) 'Managing health reform through an economic downturn', Nuffieldtrust research summary, [online] available at http://www.cfhi-fcass.ca/sf-docs/defaultsource/canadian-masterclass-presentations/2011-10ManagingHealthReformEconomicDownturn.pdf?sfvrsn=0. Accessed [18.12.2014]. 
van Heerde, H.J., Gijsenberg, M., Dekimpe, M.G. and Steenkamp, J-B.E.M. (2013), 'Price and advertising effectiveness over the business cycle,' Journal of Marketing Research, 50 (2), 177-193.

Wagstaff, A. (2009), 'Social health insurance versus tax-financed health systems - Evidence from the OECD', World Bank Policy Research Working Paper 4821. 